NPS-GSBPP-14-002
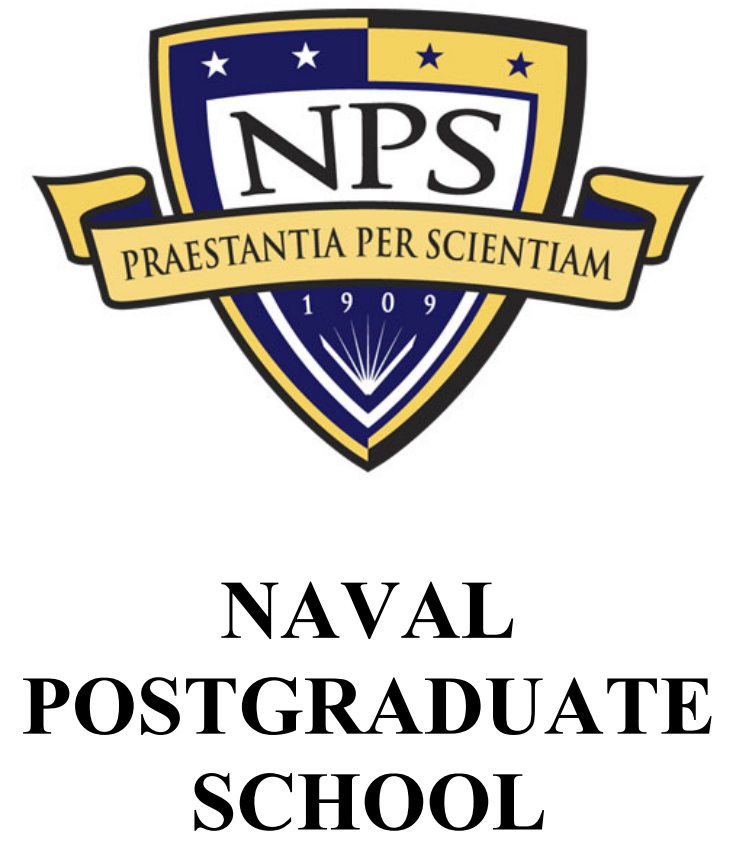

MONTEREY, CALIFORNIA

CASE: THE GLOBAL POSITIONING SYSTEM (GPS)

by

Jesse M. Cunha and Katherine LoPiccalo

May 2014

Approved for public release; distribution is unlimited 
THIS PAGE INTENTIONALLY LEFT BLANK 
THIS PAGE INTENTIONALLY LEFT BLANK 
NAVAL POSTGRADUATE SCHOOL

Monterey, California 93943-5000

Ronald A. Route

Douglas A. Hensler

President

Provost

The report entitled "Case: The Global Positioning System (GPS)" was prepared for the Naval Postgraduate School.

Further distribution of all or part of this report is authorized.

This report was prepared by:

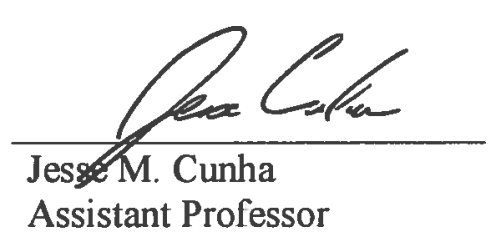

Reviewed by:

GATES.WILLIAM

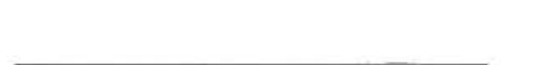

William Gates,

Dean of Graduate School

Of Business and Public Policy

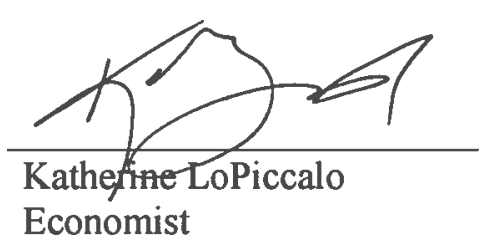

Released by:

Jeffrey D. Paduan

Dean of Research 
THIS PAGE INTENTIONALLY LEFT BLANK 


\title{
Case: The Global Positioning System (GPS) ${ }^{*}$
}

\author{
Graduate School of Business and Public Policy
}

Naval Postgraduate School

\footnotetext{
${ }^{*}$ This case was developed and written by Professor Jesse M. Cunha and Katherine LoPiccalo. Professor Cunha is an Assistant Professor of Economics at the Naval Postgraduate School's Graduate School of Business and Public Policy and Katherine LoPiccalo is an Economics Ph.D. candidate at the University of California, Santa Cruz. The information in this case is based on public documents and is not intended as a source of primary data; it was developed solely to facilitate classroom discussion.
} 


\section{Overview}

The Global Positioning System (GPS) is a satellite-based navigation system developed in the 1960s by the U.S. Navy and currently maintained by the U.S. Air Force. GPS consists of a "constellation" of around 30 satellites orbiting at 12,000 miles above the surface of the Earth; each satellite circles the globe once every 12 hours. Throughout their orbit, these satellites broadcast radio signals to Earth and record the exact time and location (in space) that the signal was transmitted.

On the ground, GPS receivers can use the difference between the radio signals from four or more satellites to determine their own location, speed, and/or elevation. Commercially available handheld GPS receivers allow a user to determine their position anywhere on the globe with incredible accuracy. Combined with a computerized map, a receiver can identify its exact location to within 30 feet.

We can categorize the modern GPS system as consisting of three segments: space (the satellite array in space), control (the ground-based control of those satellites), and user (the end-user of satellite signals). The space segment simply refers to the constellation of satellites that transmit radio signals to users. The control segment consists of a "global network of ground facilities that track the GPS satellites, monitor their transmissions, perform analyses, and send commands and data to the satellites" (www.gps.gov); presently, this segment includes a master control station, an alternate master control station, 12 command and control antennas, and 16 monitoring sites. The user segment consists of all of the equipment receiving signals from GPS satellites.

GPS supports a wide range of civil, scientific, and commercial functions. Beyond the obvious application of navigation for the general public, James (2009) summarizes some other examples nicely. He writes: "Meteorologists gauge wind speed and other variables by measuring satellite signals as they pass through the atmosphere; geologists study earthquakes using GPS receivers placed along fault lines; and ... GPS also plays a major role in military combat, guiding missiles and bombs to their destinations in Iraq, Afghanistan and elsewhere."

Although "positioning" is an obvious application of the technology, GPS signals have also become a crucial timekeeper for the financial industry. Transactions made everywhere, from ATMs to Wall Street stock trades, are time-stamped using the precise atomic clocks ticking within the GPS satellites, clocks which are accurate to one-billionth of a second. Thus, GPS technology likely confers huge benefits to an industry where billions of dollars can be made or lost in a fraction of a second.

Despite these obvious civilian uses, up until the year 2000 the U.S. military had significantly restricted the accuracy of GPS signals due to national security concerns. By design, satellite signals are freely available to anyone anywhere in the world with a receiver; that is, the signals cannot be blocked. Therefore, the U.S. military scrambled (or encrypted) the GPS signal at its source, effectively limiting its use to only those with access to government-issued decryption technology. Others had access to the limited, much less accurate "public" signal. 
It is important to note that the GPS system was developed by the U.S. government solely for military use and national defense. Furthermore, the fact that a GPS system for civilian and commercial use was not developed in the private market is a testament to the enormous cost of developing, building, and launching over two dozen satellites, in addition to the cost of ground control systems. Perhaps it would not have been profitable for the private market to provide a good like GPS.

Furthermore, it is important to note that expected upgrades to the system are projected to enter into the billions of dollars. According to www.gps.gov, the current GPS satellites (called Block II generation satellites) desperately need to be upgraded. Block III satellites are being developed and tested by Lockheed Martin as part of a \$5.5 billion dollar upgrade that will be completed in 2014 (Newman 2011). The new system will provide increased signal strength, reliability, and integrity, as well as improving accuracy to within 3 feet. Lockheed Martin is currently under contract to build four GPS III satellites, with options to build an additional eight satellites.

Given the size and scope of the GPS system, and the fact that it is publicly provided, there are important questions that must be asked, such as: Is it optimal for the U.S. government to provide and maintain the GPS system? What would happen if the U.S. decided to stop maintaining and not upgrade the GPS satellites? This case proceeds to detail the history of the GPS system and outline the policy decisions that were made in the past. This information should prove useful for analyzing crucial multi-billion dollar policy questions concerning GPS that we face today.

\section{Origins of GPS 1}

The origin of the GPS system, more formally known as the Navigation System for Timing and Ranging (NAVSTAR), can be traced back to the Soviet launch of the satellite Sputnik on Oct. 4, 1957. At the height of the Cold War, Sputnik's launch was a milestone that both excited the American scientific community and dismayed the U.S. military. It particularly caught the attention of researchers at the Johns Hopkins' Applied Physics Laboratory (APL), who immediately began trying to figure out a way to "listen in" on the satellite's signals.

On the Monday following Sputnik's Friday launch, researchers William Guier and George Weiffenbach worked out a way to track Sputnik's orbit using changes in the satellite's radio frequency as it moved closer and then further away from them as it orbited Earth. Their tracking mechanism utilized what is known as the Doppler effect. ${ }^{2}$

\footnotetext{
${ }^{1}$ The historical material in this section and the next has been summarized from the following sources: Guier and Weiffenbach (1998); APL Technical Digest (1998); Danchick (1998); Pace et al. (1995); McGee (1999)

${ }^{2}$ A commonly used example of the Doppler effect involves a speeding ambulance approaching a stationary pedestrian. The pitch of the siren changes as the ambulance approaches, and again as it passes the pedestrian. In principle, one could determine the location and speed of the ambulance using only the changes in the pitch of the siren.
} 
Five months after their work on Sputnik, Guier and Weiffenbach were asked by a colleague to apply their tracking technique toward another problem. APL researcher Frank McClure had been working with the Navy's Special Projects Office on Polaris nuclear submarines. Specifically, McClure had been tasked by the Navy to overcome what was later referred to as the "navigation problem." Namely, in order to fire a missile from sea at a target with any accuracy, the submarine would need to keep precise track of its own location at any given time. Solving the navigation problem required submarines to be aware of their precise positional location.

McClure realized that if the Guier and Weiffenbach's tracking method could be inverted, it had the potential to provide the solution. McClure directed Guier and Weiffenbach to begin applying the inverted Doppler method to the Navy's problem. The researchers soon discovered that if the satellite in question was "cooperative" (that is, if one knew where it was at all times), and broadcast two frequencies that were both very stable and sufficiently high, the Navy would be able to track its submarines with incredibly high accuracy.

After confirming Guier and Weiffenbach's initial results, McClure and a systems engineer named Richard Kershner began designing the Navy's TRANSIT Navigation System - the forerunner of NAVSTAR GPS.

\subsection{U.S. Navy's TRANSIT and TIMATION}

The Navy's TRANSIT system that Kershner designed consisted of: (1) multiple polar orbiting satellites radiating two frequencies to provide navigation information; (2) a satellite tracking system to receive those two frequencies; and (3) a station to transmit the resulting orbit parameters to each satellite.

TRANSIT began operation in January 1964 with five satellites. More than 12 satellites were eventually launched; seven operated full-time, while five were in-orbit back-up systems. TRANSIT provided worldwide positional information for Navy ships and submarines with ballistic capabilities. Fleet ships could get a fix on their location between every eight and 20 minutes, accurate to within 25 meters.

While TRANSIT was a successful application of satellite navigation capabilities, the Navy began immediately exploring other, more responsive tracking systems. The product of these efforts was a project called TIMATION (an amalgam of "time" and "navigation"). While TRANSIT utilized Doppler navigation to provide tracking information, TIMATION relied on time navigation and passive ranging to provide positional location. Through the use of satellite-carried atomic clocks, circular orbits and a constellation of high-precision space clocks, passive ranging could provide more accurate and instantaneous satellite navigation information. The first TIMATION satellite launched in 1967. 


\subsection{U.S. Air Force's Project 621B}

Concurrent to the U.S. Navy, the U.S. Air Force began its own work in satellite-based navigation. TRANSIT was adequate for the Navy's large, slow-moving ships and submarines, but the Air Force required a more complex system for its fast-moving aircraft. Further, the Air Force wanted a navigation system which did not require additional calculation in the cockpit, as well as one which provided a continuous positional location.

In late 1963, the Air Force began working on a positioning system with three-dimensional (latitude, longitude, and altitude) navigation and continuous service. Project 621B, as it was known, would also make use of a new type of satellite ranging signal based on pseudorandom noise (PRN) - later incorporated into the modern GPS system.

The Air Force envisioned 621B as a global system consisting of 16 satellites in geosynchronous orbits that could provide 24-hour coverage of a particular geographic region (for example, North and South America). However, it would be at least a decade until the Air Force would be able to realize a navigation system sufficient for their purposes.

\subsection{Modern GPS}

In the late 1960s, at least four government agencies were developing or upgrading competing satellite navigation systems: 1) the Navy was pushing to expand TIMATION; 2) the Air Force was developing Project 621B; 3) the U.S. Army had proposed using its own system, called SECOR (Sequential Correlation of Range), and; 4) the APL at Johns Hopkins was making technical improvements to TRANSIT and looking into upgrading the system.

In an attempt to streamline the process, the U.S. Department of Defense established a joint steering committee in 1968 to coordinate the efforts of the various satellite navigation groups. The committee "spent the next several years deciding what the specifics of a satellite navigation system should be - how many satellites, at what altitude, signal codes, and modulation techniques - and what they would cost" (Pace et al. 1995).

In April 1973, the Air Force was chosen to consolidate the government's various satellite navigation projects into a single comprehensive (DoD) program known as the Defense Navigation Satellite System (DNSS). By September 1973, a compromise system which combined the "best" features of both the earlier Navy and Air Force projects was developed. In December 1973, the DoD approved the joint steering committee's recommendation on what is now known as the NAVSTAR Global Positioning System. 


\section{Civilian Use}

Civilian use of the precursors to the modern GPS system was limited, but not uncommon. In fact, the Navy's TRANSIT was made available to commercial marine navigators and the owners of small pleasure boats as early as 1967. However, civilian use of the modern GPS system was severely restricted until 1983.

Satellite navigation had been developed primarily as a system for national defense. By default, GPS was a proprietary technology of the U.S. government. Using innovation and research from private sector scientists, the U.S. government had borne the cost of building, developing and maintaining the entire system. The global reach of GPS made it both a powerful asset for military defense and a potential weapon. Military officials were hesitant to release the technology to the general public for fear it would be used against American assets.

In September 1983, however, Soviet fighter aircraft shot down Korean Air Flight 007 after the passenger plane had unknowingly strayed into Soviet-controlled airspace. Accurate tracking and positional data - which could have prevented the accident - were not available to the civilian aviation industry at the time. Thus, in order to prevent future incidents, President Reagan announced that NAVSTAR GPS would be made available for civilian use (in all domestic and international markets) once the system became fully operational.

Yet the reservations of the U.S. military remained. High-ranking officers were worried that a full release of the satellite system would put American troops or other key assets in danger. The DoD did not want the U.S. to be targeted by smart bombs using its own technology, so it sought to mitigate the risk. Instead of releasing the full signal for civilian use, the DoD encrypted the signal at its source (the satellites), introduced an accuracy error, and then released this "degraded" signal to the general public.

Specifically, the "degradation" was obtained by introducing a pseudo-random code into the encrypted military signal, inducing an error of about 50 meters horizontally and up to 100 meters vertically. The degraded signal was known as the Standard Positioning Signal; the process of signal degradation was called Selective Availability.

The U.S. and international aviation industries quickly began integrating GPS into the cockpits of their planes. In fact, GPS-based tracking became the worldwide standard following the Federal Aviation Administration's (FAA) announcement that GPS would be made available free of charge to the international community for 10 years. Even the degraded signal was thought to significantly increase the safety of passenger flights. Despite this, the FAA also began looking for ways to improve the accuracy of the Standard Positioning Signal and nullify the induced error.

The standard signal was adequate for large airports, harbors and ports with little congestion, and in good weather. Safety was significantly compromised, however, when precision paths, approaches and landings were required, or when the weather was bad.

Differential GPS, or DGPS, represented a quasi-private market response to Selective Availabil- 
ity. DGPS operated on the same principle that GPS did: Given at least two fixed stations with known, accurate positional locations, a user could correct for any induced error by differencing out the distance between the fixed stations.

While several private firms began developing their own DGPS systems in 1995 for the commercial market, most of the initial — not to mention, substantial — innovation and development of GPS came from the U.S. Coast Guard. According to McGee (1999), the Coast Guard set up DGPS along U.S. coastlines and near harbors as early as 1996. The service was provided free of charge in the interest of public safety.

In 1997, not only did the FAA begin development of its own DGPS system for major airports, it began working on a nationwide DGPS system (called the Wide Area Augmentation System, or WAAS) to improve the accuracy, integrity and strength of the standard signal.

DGPS increased the strength of the standard signal, and could provide positional data with nearly the same accuracy as the full military signal. In 1999, sensing they were losing control of the dual-user system, the DoD approved a new civil signal in the next-generation of GPS satellites for use in the aviation, transportation and maritime industries. The new signal would have the same level of accuracy as the military signal, but would still be controlled by the DoD. The official end of Selective Availability was near.

\subsection{New Era in GPS}

On May 1, 2000, President Clinton announced the end of Selective Availability. The decision likely involved the input, feedback and support of a wide variety of government agencies, consumer groups and private firms. According to the press release:

"Today ... the United States will stop the intentional degradation of the Global Positioning System (GPS) signals available to the public beginning at midnight tonight. ... The decision to discontinue SA is the latest measure in an on-going effort to make GPS more responsive to civil and commercial users worldwide. ... Worldwide transportation safety, scientific, and commercial interests could best be served by discontinuation of SA. ... The decision to discontinue SA is coupled with our continuing efforts to upgrade the military utility of our systems that use GPS, and is supported by threat assessments which conclude that setting SA to zero at this time would have minimal impact on national security. Additionally, we have demonstrated the capability to selectively deny GPS signals on a regional basis when our national security is threatened."

- President Bill Clinton, press release (May 1, 2000)

It is highly likely that the president weighed the various advantages and disadvantages of his decision. The press release goes on to say: 
"Originally developed by the Department of Defense as a military system, GPS has become a global utility. It benefits users around the world in many different applications, including air, road, marine, and rail navigation, telecommunications, emergency response, oil exploration, mining, and many more. Civilian users will realize a dramatic improvement in GPS accuracy with the discontinuation of SA. For example, emergency teams responding to a cry for help can now determine what side of the highway they must respond to, thereby saving precious minutes. This increase in accuracy will allow new GPS applications to emerge and continue to enhance the lives of people around the world."

- President Bill Clinton, press release (May 1, 2000)

In September 2007, the U.S. government announced the development of a future generation of GPS satellites. Known as the Block III generation, the satellites were developed without the Selective Availability feature. This development makes Clinton's 2000 decision to end Selective Availability permanent.

\section{GPS in the Public Domain: A Cost-Benefit Analysis}

As mentioned in the introduction, the Block III satellites are part of an approximately $\$ 5.5$ billion upgrade to both the space and control segments of GPS (Newman 2011). The U.S. government is bearing the entire cost of the new system, though presumably civilian (and military) users across the globe will benefit.

This is an important policy question that should be considered in the context of Cost-Benefit Analysis. For a system this large and expensive, we must ask ourselves: Is it optimal for the U.S. government to provide and maintain the GPS system? What would happen if the U.S. decided to stop maintaining and not upgrade the GPS satellites? Would this lead to a better outcome? A better outcome for whom?

In order to answer these important questions for current policy, it may help to consider the policy decisions that were made in the past: Reagan's 1983 to release the degraded GPS signal and Clinton's 2000 decision to end Selective Availability. What factors were important in making these decisions? What type of data did the presidents need to make an optimal decision? How did they come that that decision?

In finding answers to these questions, it may be useful to consider some of the information on the costs and benefits of the GPS system that are included in the appendix below. (Note, however, that these are not exhaustive lists and will not all necessarily be useful for the task at hand, they are simply a starting place.) 


\section{References}

[1] Bone, Dominique and Stuart Carlaw (2009). "Global Navigation Satellite Positioning Solutions" ABI Research

[2] Danchik, Robert J. (1998). “An Overview of Transit Development." Johns Hopkins APL Technical Digest, Vol 19 No. 1.

[3] Guier, William and George Weiffenbach (1998). "Genesis of Satellite Navigation.” Johns Hopkins APL Technical Digest, Vol 19 No. 1.

[4] Hennigan, W.J. May 23, 2010. “GPS is getting an \$8-billion upgrade.” Los Angeles Times.

[5] Newman, Jared. Dec. 13, 2011. "What the Next-Gen GPS Satellite Upgrade Means for You." PC World.

[6] James, Randy. May 26, 2009. “GPS.” Time Magazine

[7] .McGee, Jeffrey (Maj. U.S. Army) (1999). "Global Positioning System Selective Availability: Legal, Economic, and Moral Considerations." School of Advanced Military Studies, monograph.

[8] Pace, Scott, Gerald P. Frost, Irving Lachow, David R. Frelinger, Donna Fossum, Don Wassem, and Monica M. Pinto. (1995). “The Global Positioning System: Accessing National Policies"', Rand Corporation.

[9] Pham, Nam D. (2011). "The Economic Benefits of Commercial GPS Use in the U.S. and The Costs of Potential Disruption." NDP Consulting

[10] Selected Acquisition Report (2011). "NAVSTAR Global Positioning System." Defense Acquisition Management Retrieval (DAMIR). 


\section{A GPS System Costs}

According to data from the U.S. government's 2011 Selected Acquisition Report (SAR), operating and support costs for the space and control segments of GPS consist of:

- All costs of operating, maintaining, and supporting NAVSTAR GPS spacecraft from the Master Control station at Schriever Air Force Base in Colorado.

- All costs of operating, maintaining, and supporting NAVSTAR GPS spacecraft from the back-up Master Control station at Vandenberg Air Force Base in California.

- All costs of operating, maintaining, and supporting four dedicated GPS Ground Antennas at Cape Canaveral Air Force Station in Florida, the Kwajalein Atoll, the Ascension Islands, and Diego Garcia.

However, the figures in the SAR do not include the costs associated with shared use of remote tracking stations. Remote tracking stations are funded by the Air Force Satellite Control Network. The DoD figures also do not include the costs of launching the satellites.

The figures reported in this section include costs associated with the production, maintenance and deployment of Block IIR, IIR-M, and IIF satellites and their associated control segments. The user segment costs include costs associated with the development of two prototypes and the industrial base necessary to support the Military GPS User Equipment (MGUE) Program. 
Table 1: NAVSTAR GPS Costs: Space \& Control segment, DoD

\begin{tabular}{cccc}
\hline \hline & $\begin{array}{c}(1) \\
\text { R\&D, } \\
\text { T\&E, } \\
\text { Air Force } \\
\text { (in millions \$) }\end{array}$ & $\begin{array}{c}\text { Missile } \\
\text { Procurement } \\
\text { Air Force, } \\
\text { (in millions \$) }\end{array}$ & $\begin{array}{c}\text { Other } \\
\text { Procurement } \\
\text { Air Force, } \\
\text { (in millions \$) }\end{array}$ \\
\hline 1986 & 1.7 & - & \\
1987 & 16.9 & - & 3.3 \\
1988 & 17.8 & - & 10.2 \\
1989 & 41.8 & - & - \\
1990 & 26.5 & - & \\
1991 & 40.4 & 97.2 & \\
1992 & 40.4 & 178.4 & \\
1993 & 51.0 & 172.3 & 5.9 \\
1994 & 25.9 & 177.0 & 4.4 \\
1995 & 37.2 & 216.3 & 5.1 \\
1996 & 44.8 & 149.1 & 6.9 \\
1997 & 86.3 & 190.9 & 10.7 \\
1998 & 98.3 & 178.5 & 9.2 \\
1999 & 101.5 & 79.8 & 6.3 \\
2000 & 92.4 & 117.1 & 6.4 \\
2001 & 179.3 & 160.7 & 14.1 \\
2002 & 177.6 & 143.6 & 9.7 \\
2003 & 273.1 & 268.1 & 19.1 \\
2004 & 123.4 & 310.6 & 12.5 \\
2005 & 116.5 & 328.8 & 7.1 \\
2006 & 153.8 & 324.4 & 11.9 \\
2007 & 137.9 & 89.8 & 8.9 \\
2008 & 92.7 & 190.1 & 6.7 \\
2009 & 71.9 & 117.1 & 4.4 \\
2010 & 41.4 & 128.8 & 6.2 \\
\hline & & & \\
\hline
\end{tabular}


Table 2: NAVSTAR GPS Costs: User segment, DoD

\begin{tabular}{|c|c|}
\hline & $\begin{array}{c}\text { (1) } \\
\text { R\&D, } \\
\text { T\&E, } \\
\text { Air Force } \\
\text { (in millions \$) }\end{array}$ \\
\hline 1994 & 1.2 \\
\hline 1995 & 1.6 \\
\hline 1996 & 9.6 \\
\hline 1997 & 24.8 \\
\hline 1998 & 34.8 \\
\hline 1999 & 36.3 \\
\hline 2000 & 31.9 \\
\hline 2001 & 40.5 \\
\hline 2002 & 35.2 \\
\hline 2003 & 64.4 \\
\hline 2004 & 85.7 \\
\hline 2005 & 82.6 \\
\hline 2006 & 98.4 \\
\hline 2007 & 111.9 \\
\hline 2008 & 130.1 \\
\hline 2009 & 101.2 \\
\hline 2010 & 107.9 \\
\hline
\end{tabular}

\section{B GPS System Benefits}

Several studies have attempted to quantify the various benefits of the GPS system for various reasons. The information here comes from two studies: Pham (2011) and Bone and Carlow (2009). 
Table 3: Annual Benefits to All Commercial GPS Users in the U.S. Economy

\begin{tabular}{lcc}
\hline \hline & $\begin{array}{c}\text { Annual GPS } \\
\text { Equipment } \\
\text { Spending } \\
\text { (in billions of \$) }\end{array}$ & $\begin{array}{c}\text { Estimated } \\
\text { Annual } \\
\text { Benefits } \\
\text { (in billions of \$) }\end{array}$ \\
\hline Site-specific agriculture & $\$ 0.5$ & $\$ 19.9$ \\
Engineering construction & $\$ 1.1$ & $\$ 9.2$ \\
Transportation & $\$ 3.2$ & $\$ 10.3$ \\
(commercial surface transportation) & $\$ 4.8$ & $\$ 39.4$ \\
Other commercial GPS users & $\$ 3.5$ & $\$ 28.2$ \\
Total commercial GPS users in U.S. economy & $\$ 8.3$ & $\$ 67.6$ \\
\hline
\end{tabular}

Table 4: GPS Economic Benefits

\begin{tabular}{lc}
\hline \hline & $\begin{array}{c}(1) \\
\text { Annual spending } \\
\text { (in billions) }\end{array}$ \\
\hline Commercial GPS Users & \\
\hline Site-specific agriculture (crop farming) & $\$ 19.9$ \\
Engineering construction (heavy, civil, & $\$ 9.2$ \\
and surveying/mapping & $\$ 10.3$ \\
Transportation & $\$ 28.2$ \\
Other commercial GPS users & $\$ 8.3$ \\
\hline GPS Manufacturers & $\$ 0.5$ \\
\hline GPS Equipment sales & $\$ 19.6$ \\
R\&D spending on GPS technology & \\
\hline Other Economic Benefits & \\
\hline Book value of investment in GPS equipment & \\
\hline
\end{tabular}


Table 5: Other Direct \& Indirect Benefits

\begin{tabular}{l}
\hline \hline Spillover effects \\
\hline Emissions reductions from fuel savings \\
Nuclear detonation detection mission \\
Health and safety gains in work place \\
Worker time savings \\
Public safety and emergency response times \\
Employment in GPS-related industries and supporting industries \\
Quality-of-life improvements from consumer GPS products, services \\
Large tax base to fund federal, local government expenditures \\
\hline
\end{tabular}

Table 6: GPS Equipment Revenues by Segment, 2005-2010 (in billions)

\begin{tabular}{lcccccc}
\hline \hline & 2005 & 2006 & 2007 & 2008 & 2009 & 2010 \\
\hline Commercial & $\mathbf{\$ 4 . 6 8 6}$ & $\mathbf{\$ 6 . 5 3 8}$ & $\mathbf{\$ 8 . 7 1 9}$ & $\mathbf{\$ 9 . 9 8 0}$ & $\mathbf{\$ 9 . 3 5 3}$ & $\mathbf{\$ 1 0 . 2 9 8}$ \\
\hline Ground transport & 1.205 & 2.145 & 3.479 & 4.233 & 4.085 & 4.213 \\
Aviation & 0.209 & 0.278 & 0.314 & 0.361 & 0.271 & 0.325 \\
Machine control & 0.320 & 0.367 & 0.408 & 0.443 & 0.467 & 0.551 \\
Marine & 1.650 & 2.351 & 2.978 & 3.254 & 2.766 & 3.254 \\
People-tracking & 0.013 & 0.014 & 0.016 & 0.018 & 0.035 & 0.060 \\
Site-specific agriculture & 0.480 & 0.497 & 0.499 & 0.490 & 0.467 & 0.499 \\
Railway & 0.006 & 0.006 & 0.006 & 0.006 & 0.006 & 0.006 \\
Surveying/mapping & 0.517 & 0.563 & 0.673 & 0.736 & 0.700 & 0.833 \\
Timing/Synchron & 0.287 & 0.317 & 0.346 & 0.439 & 0.558 & 0.558 \\
\hline Non-Commercial (consumer) & $\mathbf{\$ 1 7 . 5 5 3}$ & $\mathbf{\$ 1 9 . 0 8 3}$ & $\mathbf{\$ 1 9 . 9 5 6}$ & $\mathbf{\$ 2 0 . 2 1 4}$ & $\mathbf{\$ 1 9 . 8 5 5}$ & $\mathbf{\$ 2 1 . 3 3 2}$ \\
\hline Automobile & 2.167 & 3.897 & 5.050 & 4.921 & 3.828 & 3.587 \\
Converged & 15.077 & 14.815 & 14.461 & 14.677 & 15.409 & 16.939 \\
Recreational & 0.309 & 0.371 & 0.445 & 0.616 & 0.618 & 0.807 \\
\hline Military & $\mathbf{\$ 3 . 2 4 0}$ & $\mathbf{\$ 4 . 2 5 5}$ & $\mathbf{\$ 5 . 2 8 2}$ & $\mathbf{\$ 6 . 4 4 7}$ & $\mathbf{\$ 6 . 1 2 5}$ & $\mathbf{\$ 7 . 9 8 9}$ \\
\hline TOTAL & $\mathbf{\$ 2 5 . 4 7 9}$ & $\mathbf{\$ 2 9 . 8 7 6}$ & $\mathbf{\$ 3 3 . 9 5 7}$ & $\mathbf{\$ 3 6 . 6 4 1}$ & $\mathbf{\$ 3} 35.332$ & $\mathbf{\$} 39.619$ \\
\hline
\end{tabular}




\title{
Case: The Global Positioning System (GPS) ${ }^{1}$
}

\author{
Graduate School of Business and Public Policy \\ Naval Postgraduate School \\ Graduate School of Business and Public Policy \\ Naval Postgraduate School
}

\section{Case Abstract}

\begin{abstract}
The Global Positioning System is a satellite-based navigation system developed in the 1960s by the U.S. Navy and maintained by the U.S. Department of Defense. While the practical and commercial benefits of GPS were immediately clear, its initial use was restricted to the military. The Department of Defense was concerned about terrorists or other enemies of the state using GPS to target U.S. assets and troops around the world. In 1983, however, Korean Air Flight 007 was shot down by Soviet fighters after the passenger plane had unknowingly entered into Soviet airspace. In the wake of the tragedy, President Ronald Reagan decided to release the GPS signal to the international and domestic public. Yet the concern over the potential misapplication of GPS remained, so the (positional) signal released to the public was of a degraded form with limited accuracy. This process of signal degradation was called Selective Availability. Despite the degraded form, the positioning system was in high demand, especially by the civil aviation industry. As demand increased for commercial GPS receivers, press mounted on the U.S. government to eliminate Selective Availability. In 2000, President Bill Clinton began considering whether to release the full technological capacity of GPS for civilian use. This case provides students with the institutional details surrounding the public provision of GPS, and it prompts them to consider public provision in the context of cost-benefit analysis.
\end{abstract}

\section{Teaching Objectives}

This case is intended to help students develop skills related to decision-making using cost-benefit analysis (CBA). It is the purpose of cost-benefit analysis to weigh the benefits (or justification) of an investment or policy against the potential costs of the investment (or other alternatives). For example, students may be asked to consider the potential commercial and social benefits of eliminating Selected Availability against the potential risks to national security. Students might further be asked if the potential benefits of public GPS can be achieved through alternatives that do not pose a risk to national security.

This case is intended for courses in public policy evaluation and those which consider the economic analysis of risk and uncertainty. A clear identification of the various actors involved and the stakes they face allows students to consider: 1) the impact on any participants in the process; 2) the impact on any non-participants in the process; 3) any externality effects, and; 4) potential social benefits (costs). The case assumes that there is some "better" policy among a host of available alternatives and this "best" policy can be found by implementing the cost-benefit analysis. But what is "best" for society is not always clear. Further, costs might be delineated but not well-defined.

As such, this case is intended to spur classroom discussion on at least three topics.

1. Private provision of a public good.

\footnotetext{
${ }^{1}$ This teaching note was developed for use with the Global Positioning System case study. This note was written by Professor Jesse M. Cunha and Katherine LoPiccalo. Professor Cunha is an Assistant Professor of Economics at the Naval Postgraduate School's Graduate School of Business and Public Policy and Katherine LoPiccalo is an Economics Ph.D. candidate at the University of California, Santa Cruz. The information in this note is based on public documents and is not intended as a source of primary data; it was developed solely to facilitate classroom discussion.
} 
2. Identifying and measuring the benefits of a publicly provided good.

3. Identifying and measuring the costs of hard-to-quantify risks such as those to national security.

While the instructor will have to decide the appropriate context for the issues covered in the case study, it is best to introduce the case after students have learned about the economic concepts of public goods and externalities. These concepts, particularly the arguments for (against) public vs. private provision of public goods, are sufficiently nuanced to benefit from a real-world application.

\section{Class Plan and Structure}

It is the purpose of the case study to open up a discussion on public policy evaluation in the face of risk, uncertainty, and competing objectives. While the primary goal is to encourage student discussion on goods and markets in the public sphere, the secondary goal is introduce the processes by which public officials weigh policy decisions.

In introducing the case, the instructor should clearly outline the policy question. We enumerate a possible structure below to aid the classroom discussion. In all instances, policy realization refers to the decision students come to about the policy at hand. These policies can be: allowing a de-graded GPS signal for private use, eliminating Selective Availability, or stopping public provision of GPS.

After introducing the context and history surrounding the policy question, the instructor should have the students:

1. Identify potential costs of the policy realization.

2. Identify potential benefits of the policy realization.

(a) Is it appropriate to consider only present benefits and costs? How should future benefits (such as from technological innovations) or future costs (such as from potential terrorist attacks) be incorporated?

3. Discuss how we might think about quantifying, dollar terms if possible, each cost and benefit.

The discussion can easily encompass one 140-minute session. From the above, the instructor begins by asking students to discuss the historical development of the modern GPS system. A thorough discussion should end in students coming to the conclusion that it was privately optimal for the U.S. military to develop the system. The instructor can also note an interesting twist in this case study to common examples of private vs. public provisions of public goods: here, the "private" organization in question is in fact a "public" organization. But regardless of the semantics, the economic intuition holds. This allows the instructor to discuss the importance of fitting a real-world scenario into a simple economic model to gain clarity and insight.

The instructor could then steer the discussion towards the external benefits of GPS, perhaps asking if it would make sense for the U.S. government to decrypt the GPS signal, given that it would provide huge benefits to consumers. The answer is that yes, it would provide benefits, but that comes at a cost to our national security. The instructor should let students describe how this cost - increased risk to our national interests - should be quantified.

Next comes an enumeration of the benefits of GPS. There are obviously a huge number of beneficiaries, and it would be hard to identify them all. The students should always identify the benefits to individuals, not to corporations. This discussion brings up the issue of stakeholders - should we include the benefits that accrue to citizens of other countries?

A separate issue would be to discuss whether the private market would develop and launch a separate GPS system on their own if the U.S. did not eliminate Selective Availability. This brings up several interesting questions: Could the new GPS signal be excludable? (Probably, given that the encryption technology already exists). Given that it is excludable, then the a private firm could in principle develop it profitably. 
The main issue for current policy is: Should the U.S. government still be involved in the provision of GPS? There are major upgrades that are needed in the near future, and it begs the question of whether the Department of Defense is considering privatizing the system. The downside is that they do not have exclusive control over the system. The upside is that there could be large cost savings. If GPS were privatized, the system would likely have to be regulated, as the market would have either one (a monopoly) or a few players. There are lots of issues in bringing up this question (private provision of GPS), perhaps better saved for a separate classroom discussion. 